\title{
Pengaruh Penggunaan Media Sosial dan Orientasi Kewirausahaan terhadap Kinerja UMKM
}

\author{
Kevin dan Ida Puspitowati \\ Program Studi S1 Manajemen Fakultas Ekonomi dan Bisnis \\ Universitas Tarumanagara \\ Email: kevincen15@gmail.com
}

\begin{abstract}
This research was conducted to study Social Media and Entrepreneurial Orientation on the performance of culinary business performance in Grogol and Mangga Besar, West Jakarta.The research design is causal with a total sample of 40 respondents, the sampling technique uses non-probability sampling method. This Data was processed using the Smart PLS 3.0 program.The results of this study indicate a significant influence between social media and entrepreneurial orientation that uses in culinary business in Grogol and Mangga Besar, West Jakarta.
\end{abstract}

Keywords: Social media, entrepreneurial orientation, performance

Abstrak: Penelitian ini dilakukan untuk mengetahui pengaruh Penggunaan Media Sosial dan Orientasi Kewirausahaan terhadap Kinerja UMKM kuliner di Grogol dan Mangga Besar, Jakarta Barat. Desain penelitian adalah kausal dengan jumlah sampel sebanyak 40 responden, teknik pengambilan sampel menggunakan metode non-probabilitysampling. Data diproses dengan menggunakan program Smart PLS 3.0.Hasil penelitian ini menunjukan bahwa adanya pengaruh yang signifikan antara penggunaan media sosial dan orientasi kewirausahaan terhadap kinerja UMKM kuliner di Grogol dan Mangga Besar, Jakarta Barat.

Kata kunci:Media sosial, orientasi kewirausahaan, kinerja

\section{LATAR BELAKANG}

Perkembangan zaman dan kemajuan perekonomian di Indonesia yang sangat pesat membuat dunia bisnis sekarang ini dituntut untuk mengambil langkah strategis agar dapat bersaing dengan bisnis lainnya, khususnya Usaha Mikro Kecil dan Menengah (UMKM). Hal ini dikarenakan UMKM memiliki lingkungan bisnis yang penuh dengan ketidak pastian. UMKM juga mempunyai peranan penting dalam pembangunan ekonomi di Indonesia baik segi usaha maupun penciptaan lapangan kerja.

UMKM yang berkembang pesat saat ini merupakan UMKM yang bergerak di sektor industri makanan dan minuman, sekaligus memiliki potensi terbesar dalam pendapatan nasional di bidang ekonomi. Sektor kuliner merupakan jenis usaha yang akan berjalan sepanjang masa karena merupakan kebutuhan pokok yang dibutuhkan oleh manusia. Kategori sektor industri kuliner mecakup makanan ringan, makanan pokok dan minuman.

Pada saat ini, pemanfaatan perkembangan teknologi informasi banyak digunakan untuk mengembangkan bisnis baik dari perusahaan maupun individu dimana teknologi informasi berbasis jejaring sosial banyak dimanfaatkan untuk pengembangan bisnis. Media sosial saat ini merupakan trend anak muda untuk mengekspresikan diri menjadi peluang yang sangat besar bagi suatu bisnis untuk dimanfaatkan sebagai media periklanan maupun promosi. Hal 
ini terbukti dengan banyaknya usaha yang mencoba menawarkan berbagai produk menggunakan media sosial (Wijaya, 2011).

Usaha Mikro Kecil dan Menengah (UMKM) merupakan penggerak perekonomian di Indonesia, baik dalam skala daerah maupun nasional karena berdasarkan data yang ada pada Badan Pusat Statistik (2017), jumlah Usaha Mikro Kecil dan Menengah dapat berkembang menjadi 59 juta unit serta mampu memberikan kontribusi pada PDB (Produk Domestik Bruto) nasional sebesar 60,34\%. Sehingga membuat unit Usaha Mikro Kecil dan Menengah menjadi solusi dalam menciptakan banyak lapangan pekerjaan.

Menurut Goh dkk.(2013) untuk mengelola aliran dan hubungan rantai pasokan mereka denganbaik, perusahaan baru-baru ini mengadopsi perkembangan Teknologi Informasi dan Komunikasi terkini di sekitar media sosial untuk menjangkau kumpulan besar pelanggan potensial dan mitra serta untuk meningkatkan keunggulan kompetitif.

Keh dkk. (2007) menunjukkan bahwa orientasi kewirausahaan memiliki efek langsung pada kinerja perusahaan. Kraus (2013) adanya hubungan positif yang signifikan dimana orientasi kewirausahaan terhadap kinerja bisnis dari sektor jasa secara umum. Smart dan Conant (1994) mengidentifikasi bahwa orientasi kewirausahaan dan kinerja memiliki keterkatian secara signifikan pada sektor ritel.

\section{KAJIAN TEORI}

Penggunaan Media Sosial. Hsu (2012) mendefinisikan penggunaan media sosial sebagai tempat berkumpulnya sejumlah besar konsumen, gudang informasi milik pelanggan yang berfungsi menyebarkan informasi untuk membangun kehadiran pasar. Pendapat Paridon dan Carraher (2009) media sosial adalah metode biaya-efektif untuk kegiatan pemasaran. Dari penjelasan tersebut penggunaan media sosial merupakan suatu inovasi yang diterapkan perusahaan untuk menjangkau pelanggan potensial, mempermudah penyebaran informasi serta berguna untuk meningkatkan keunggulan kompetitif dan berfungsi untuk menjaga hubungan baik dengan berbagai pihak.

Orientasi Kewirausahaan. Lumpkin dan Dess (1996) mengemukakan bahwa orientasi kewirausahaan adalah tingkat keberanian seorang wirausaha untuk menjadi yang pertama dalam inovasi produk, melakukan Tindakan proaktif dan mandiri dalam menjalankan usaha serta berani mengambil resiko. Berdasarkan uraiandiatas, maka dapat disimpulkan bahwa orientasi kewirausahaan adalah suatu kemampuan dan karakteristik yang dimiliki oleh seorang wirausaha seperti sifat pantang menyerah serta memiliki inovasi dan berani dalam mengambil resiko menjalankan sebuah usaha.

Kinerja. Kinerja usaha menurut Moullin (2007) adalah suatu tolak ukur seberapa baik suatu perusahaan dikelola dan nilai yang disalurkan olehperusahaan bagi pemangku kepentingan maupun pelanggan. Berdasarkan pendapatdiatas, maka kinerja adalah suatu ukuran kesuksesan bagi seorang individu maupun suatu perusahaan yang ditunjukkan dari meningkatnya hasil kerja baik dari sisi kuantitas maupun kualitas.

Kaitan Penggunaan Media Sosial terhadap Kinerja UMKM. Li dan Bernoff (2008) mendefinisikan penggunaan sosial sebagai sumber daya di perusahaan dapat membantu perusahaan meningkatkan kapasitas organisasinya dengan menyediakan komunikasi instan melalui saluran multimedia yang berbeda. Menurut Zarella (2010) penggunaan media sosial diargumentasikan sebagai media yang tepat bagi pemasaran karena kemudahan akses, penggunaan media sosial merupakan langkah strategis dalam memasarkan hasil produk. Rodriguez, dkk (2016) penggunaan media sosial di dalam suatu perusahaan mampu 
meningkatkan pendapatan, meningkatkan penjualan, meningkatkan hubungan dengan pelanggan serta citra merek perusahaan.

Ha1: Penggunaan Media Sosial memiliki pengaruh yang positif signifikan terhadap Kinerja UMKM

Kaitan Orientasi Kewirausahaan terhadap Kinerja UMKM. Wiklund danShepherd (2003) mengemukakan suatu perusahaan yang merangkul atau menerapkan orientasi kewirausahaan akan lebih efektif berjalan daripada perusahaan yang tidak menerapkannya.Keh dkk. (2007) menunjukkan bahwa tingkat orientasi kewirausahaan memiliki efek langsung pada kinerja perusahaan. Kraus (2013) adanya hubungan positif yang signifikan dimana orientasi kewirausahaan terhadap kinerja bisnis dari sektor jasa secara umum. Smart dan Conant (2014) mengidentifikasi bahwa orientasi kewirausahaan dan kinerja memiliki keterkatian secara signifikan pada sektor ritel

Ha2: Orientasi kewirausahaan memiliki pengaruh yang positif signifikan terhadap Kinerja UMKM

Hipotesis dari model yang dibangun adalah sebagai berikut:

$\mathrm{Ha}_{1}$ : Terdapat pengaruh positif Penggunaan Media Sosial terhadap Kinerja UMKM Kuliner di Jakarta Barat

$\mathrm{Ha}_{2}$ : Terdapat pengaruh positif Orientasi Kewirausahaan terhadap Kinerja UMKM kuliner di Jakarta Barat

\section{METODOLOGI}

Desain penelitian adalah sebuah kerangka atau rencana kerja untuk melakukan penelitian yang akan digunakan sebagai pedoman dalam mengumpulkan dan menganalisis data. Desain penelitian terdiri dari tigajenis, yaitu exploratory, descriptive dan causal study (Sekaran dan Bougie, 2016).Penelitian ini menggunakan desain penelitian kausal dimana desain penelitian kausal berguna untuk mengetahui sebab akibat atau menganalisa hubungan antara satu variabeldengan variabel lainnya atau bagaimana suatu variabel mempengaruhi variabel lainnya (Supranto, 2012)

Dalam penelitian ini digunakan metode kuantitatif dengan pendekatan cross-sectional karenamerupakan pendekatan ilmiah yang memandang suatu realitas dapat diklasifikasikan, terukur dan teramati dimana data penelitiannya berupa angka dan analisis (Sugiyono, 2012).Pendekatan cross-sectional merupakan data yang dapat menjawab pertanyaan penelitian dan hasil penelitian dapat dilihat dalam waktu beberapa hari, minggu dan bulan serta dapat dikumpulkan hanya dalam waktu satu kali (Sekaran dan Bougie, 2010).

Populasi dalam penelitian ini adalah pelaku UMKM kuliner di Jakarta Barat dalam bentuk kuesioner. Teknik pemilihan sampel dalam penelitian ini dengan metode non probability sampling dengan teknik purposive sampling. Pemilihan elemen untuk menjadi anggota sampel dalam penelitian ini berdasarkan pertimbangan tidak acak atau sesuai dengan penilaian (Suryani dan Hendryadi, 2015, h. 210). Ukuran sampel yang ideal adalah di antara 30-500 responden, Jika sampel dipecah lagi ke dalam subsample seperti laki-laki atau perempuan, jumlah minimum subsample harus 30, Pada penelitian multivariate, ukuran sampel harus beberapa kali lebih besar (10 kali) dari variabel yang akan di analisis. Pada penelitian ini, terdapat 3 variabel penelitian. Maka, jumlah sampel minimumnya sebesar 30 
responden. Peneliti ini memiliki responden dengan karakteristik pelaku UMKM kuliner di Jakarta Barat sebanyak 40 responden. Skala yang digunakan dalam penelitian ini ialah skala likert. Skala likert merupakan skala yang digunakan secara luas yang meminta responden menandai derajat kesetujuan atau ketidaksetujuan terhadap masing-masing dari serangkaian pernyataan tentang objek stimulus (Malhotra, 2020).

\section{HASIL UJI STATISTIK}

Berikut ialah hasil uji statistic dari hasil uji akan diketahui semua variabel dapat diterima atau valid.

Tabel 1. Hasil Analisis Average Variance Extracted (AVE)

\begin{tabular}{|c|c|c|}
\hline Variabel & $\begin{array}{c}\text { Average Variance Extracted } \\
\text { (AVE) }\end{array}$ & Hasil \\
\hline $\begin{array}{c}\text { Penggunaan Media } \\
\text { Sosial }\end{array}$ & 0,634 & Valid \\
\hline Orientasi Kewirausahaan & 0,653 & Valid \\
\hline Kinerja UMKM & 0,662 & Valid \\
\hline
\end{tabular}

Sumber: Pengolahan Data SmartPLS 3.0

Berdasarkan Tabel 1 di atas maka dapat disimpulkan bahwa Penggunaan media sosial, orientasi kewirausahaan dan kinerja UMKM memiliki nilai AVE >0,5 dengan angka pada penggunaan media sosial $(0,634)$, orientasi kewirausahaan $(0,653)$ dan kinerja UMKM dengan angka $(0,662)$.

Tabel 2. Hasil Pengujian Validitas

\begin{tabular}{|c|c|c|c|}
\hline & $\begin{array}{c}\text { Penggunaan Media } \\
\text { Sosial }\end{array}$ & $\begin{array}{c}\text { Orientasi } \\
\text { Kewirausahaan }\end{array}$ & Kinerja UMKM \\
\hline MS1 & 0,788 & & \\
\hline MS2 & 0,788 & & \\
\hline MS3 & 0,821 & & \\
\hline MS4 & 0,814 & & \\
\hline MS5 & 0.836 & & \\
\hline MS7 & 0,795 & 0,849 & \\
\hline MS8 & 0,726 & 0,823 & \\
\hline OK1 & & 0,797 & \\
\hline OK2 & & & \\
\hline OK4 & & & \\
\hline
\end{tabular}




\begin{tabular}{|c|c|c|c|}
\hline OK5 & 0,731 & \\
\hline OK6 & & 0,835 & \\
\hline OK7 & & 0,807 & 0,800 \\
\hline KU1 & & & 0,817 \\
\hline KU2 & & & 0,820 \\
\hline KU3 & & & 0,816 \\
\hline KU4 & & & \\
\hline
\end{tabular}

Sumber: Pengolahan Data SmartPLS 3.0

Berdasarkan Tabel 2 dapat dijelaskan bahwa hasil uji validitas variabel penggunaan media sosial, orientasi kewirausahaan dan kinerja UMKM yang sudah memiliki nilai loading factor $>0,7$ memiliki validitas yang tinggi terdapat pada variabel MS1, MS2, MS3, MS4, MS5, MS7, MS8, OK1, OK2, OK4, OK5, OK6, OK7, KU1, KU2, KU3 dan KU4. Untuk indikator yang memiliki nilai $<0,7$ dihilangkan agar seluruh indikator pada setiap variabel dapat valid atau merefleksikan variabelnya.

Tabel 3. Hasil Pengujian Reliabilitas

\begin{tabular}{|c|c|c|c|}
\hline Variabel & Cronbach's alpha & Composite Reability & Keterangan \\
\hline Penggunaan Media Sosial & 0,924 & 0,903 & Reliabel \\
\hline Orientasi Kewirausahaan & 0,918 & 0,893 & Reliabel \\
\hline Kinerja UMKM & 0,887 & 0,830 & Reliabel \\
\hline
\end{tabular}

Sumber: Pengolahan Data SmartPLS 3.0

Berdasarkan tabel uji reliabilitas pada tabel 3, menampilkan hasil pengujian dari tiga variabel yang digunakan, diketahui hasil dari pengujian cronbach's alpha pada setiap variabelnya mendapatkan hasil lebih dari $6(>0.6)$ dan juga nilai composite reability mendapatkan hasil lebih dari 0.7 yang dapat disimpulkan bahwa dengan hasil dari masingmasing variabelnya sudah memenuhi kriteria analisis reliabilitas (Hussein, 2005).

Setelah data-data melewati uji outer model pengolahan data variabel-variabel penelitian dilanjutkan pada tahapan pengujian model struktural untuk dapat mengetahui kontribusi dari variabel-variabel independen $(\mathrm{X})$ terhadap variabel-variabel dependen (Y). Berikut merupakan kriteria pengujian model struktural yang harus dipenuhi pada penelitian ini yaitu nilai koefisien determinasi $\left(\mathrm{R}^{2}\right)$, predictive relevance $\left(\mathrm{Q}^{2}\right)$ dan path coefficients.

Nilai $R$-square juga digunakan untuk menilai variasi pengaruh antara variabel independen terhadap variabel dependen (Ghozali, 2014). Hasil pengujian analisis koefisien determinasi $\mathrm{R}^{2}$ pada penelitian ini adalah sebesar 0,744 yang menjelaskan bahwa $74,4 \%$ variabel kinerja UMKM dapat dijelaskan oleh variabel penggunaan media sosial dan orientasi kewirausahaan sedangkan sebanyak 25,6 \% dijelaskan oleh variabel lainnya yang tidak di teliti dalam penelitian ini.Nilai R-Square yang didapatkan dari hasil penelitian ini memiliki pengaruh yang tergolong kuat. 
Uji selanjutnya adalah effect size (f2) dan hasil yang di uji yaitu variabel penggunaan media sosial terhadap kinerja UMKM adalah sebesar 0,194 dan variabel orientasi kewirausahaan terhadap kinerja UMKM sebesar 0,205. Menurut Ghozali (2014) dapat disimpulkan bahwa variabel penggunaan media sosial memiliki hubungan yang kuat terhadap kinerja UMKM begitu juga dengan variabel orientasi kewirausahaan memiliki hubungan yang kuat pula dengan kinerja UMKM.

Uji selanjutnya adalah predictive relevance $\left(Q^{2}\right)$ dan hasil yang didapatkan adalah 0,476 yang artinya konstruk variabel yang telah dilakukan penelitian memiliki hasil yang dianggap relevan dan dapat digunakan untuk mengukur model penelitian yang sudah terbentuk sebelumnya dengan baik. Uji berikutnya adalah Goodness of Fit (GoF), hasilnya yaitu sebesar 0.695 yang menurut pendapat Ghozali (2014) penelitian ini mempunyai kecocokan model penelitian yang tergolong besar.

Tabel 4. Hasil Bootstrapping

\begin{tabular}{|c|c|c|c|}
\hline Variabel & Original Sample & T Statistics & P values \\
\hline Penggunaan media sosiał & 0,441 & 2,689 & 0,007 \\
Kinerja UMKM & & & \\
\hline $\begin{array}{c}\text { Orientasi kewirausahaan } \rightarrow \\
\text { Kinerja UMKM }\end{array}$ & 0,453 & 2,722 & 0,007 \\
\hline
\end{tabular}

Sumber: Pengolahan Data SmartPLS 3.0

Berdasarkan Tabel 4 di atas hasil pengujian bootstrapping (hipotesis) dari seluruh variabel dengan nilai t-statistics $>1,645$ dan nilai $\mathrm{p}$-values $<0,05$ yang dinyatakan hipotesis tidak ditolak atau dinyatakan signifikan.

a. Hubungan antara penggunaan media sosial (X1) dengan kinerja UMKM (Y) adalah signifikan dengan $\mathrm{T}$ statistic 2,689 $(>1,645)$ serta $\mathrm{P}$ value $0,007(<0,05)$ dan nilai original sample adalah positif yaitu 0,441 maka arah hubungan antara penggunaan media sosial X1 dengan kinerja UMKM (Y) yaitu positif dan signifikan.

b. Hubungan antara orientasi kewirausahaan (X2) dengan kinerja UMKM (Y) adalah signifikan dengan $\mathrm{T}$ statistic $0,453(>1,645)$ serrta $\mathrm{P}$ value $0,007(<0,05)$ dan nilai original sample adalah positif yaitu 0,453 maka arah hubungan antara orientasi kewirausahaan (X2) dengan kinerja UMKM (Y) yaitu positif signifikan. 


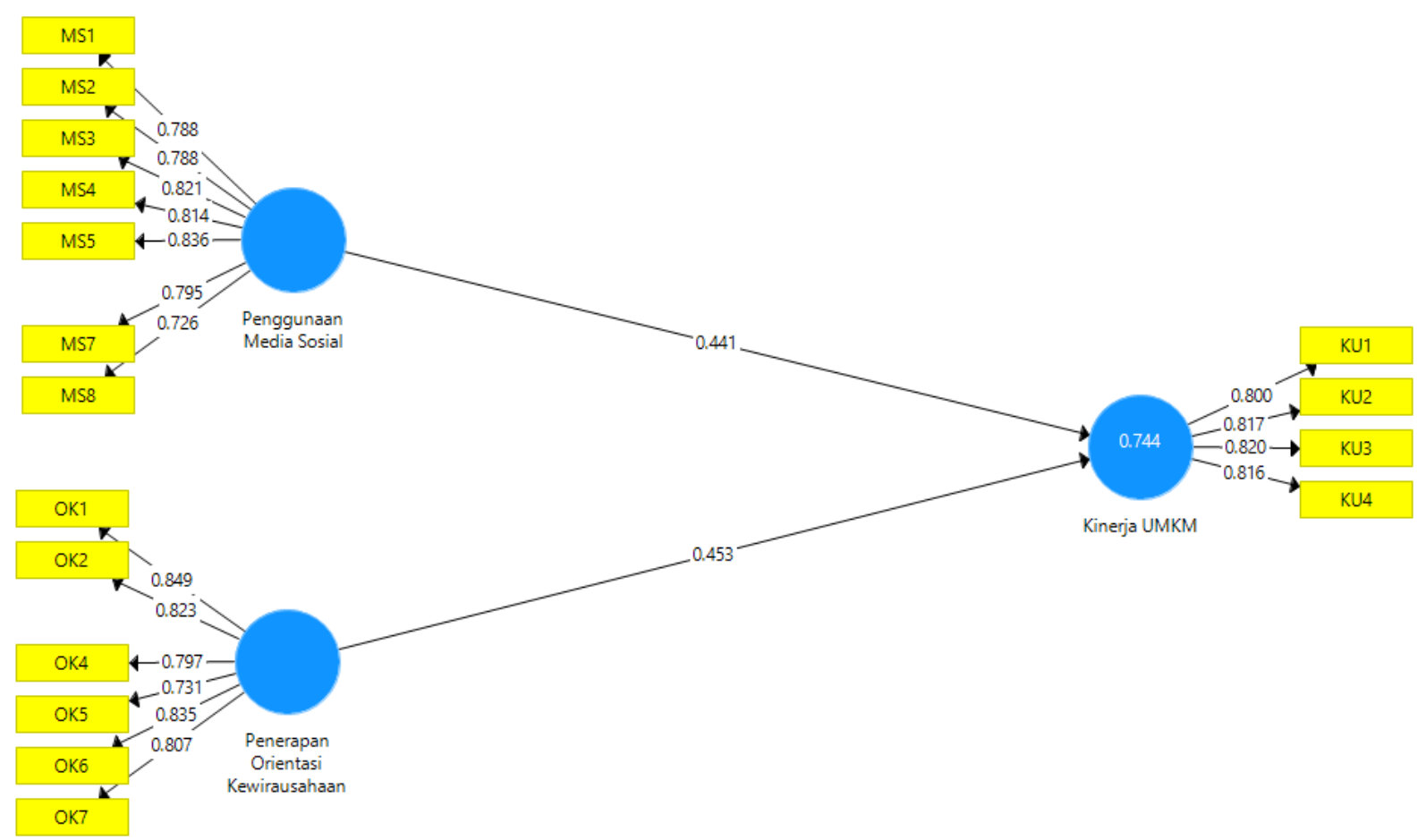

Sumber: Pengolahan Data SmartPLS 3.0

Gambar 1. Hasil Bootstrapping

\section{DISKUSI}

Penelitian yang dilakukan oleh Aziz dkk. (2018) dengan judul"Analisis Penggunaan Media Sosial Instagram dan Pengaruhnya Terhadap Business Performance Satisfaction" terhadap 80 UMKM kuliner di kota Malang, tujuan dari penelitian ini untuk mengetahui pengaruh pemanfaatan media sosial oleh UMKM kuliner terhadap kepuasan kinerja bisnis yang dirasakan.Dengan menerapkan media sosial dalam UMKM dapat juga meningkatkan kemampuan UMKM dalam membangun persona digital dan menjaga hubungan dengan pelanggan dan juga dapat membantu dalam penjualan suatu UMKM.

Penelitian yang dilakukan oleh Nurlita (2017), tujuan dari penelitian ini untuk menganalisis pengaruh orientasi kewirausahaan dan inovasi produk terhadap kinerja pemasaran Kelompok Usaha Bersama (KUB) gerabah di Desa Bumi, Serang, Banten. Sampel yang digunakan pada penelitian ini yaitu 61 pengrajin gerabah di Desa Bumi, hasil penelitian ini menunjukkan bahwa orientasi kewirausahaan memiliki pengaruh yang signifikan terhadap kinerja pemasaran KUB serta inovasi memiliki pengaruh yang signifikan terhadap kinerja KUB di Desa Bumi, Serang, Banten.

Sofyan (2017), dengan mengambil sampel 70 responden (pemilik sekaligus pengelola) UMKM di Kabupaten Serang. Tujuan dari penelitian ini untuk menguji dan menganalisis pengaruh media sosial dan orientasi kewirausahaan terhadap kinerja pemasaran. Hasil penelitian ini menunjukkan penggunaan media sosial dan orientasi kewirausahaan memiliki pengaruh signifikan terhadap kinerja pemasaran.

Hasil dari pengujian hipotesis dalam penelitian ini menunjukkan terdapat pengaruh positif dan signifikan antara variabel penggunaan media sosial terhadap kinerja UMKM 
bidang kuliner di Jakarta Barat. Pada orientasi kewirausahaan terdapat pengaruh positif dan signifikan terhadap kinerja UMKM bidang kuliner di Jakarta Barat.

KESIMPULAN

Berdasarkan hasil pengujian data dalam penelitian ini, menunjukan bahwa penggunaan media sosial berpengaruh positif dan signifikan terhadap kinerja UMKM kuliner di Jakarta Baratyang berarti bahwa penggunaan media sosial dalam UMKM sangat mendukung dan mempengaruhi kinerja dari suatu UMKM serta Orientasi kewirausahaan juga memiliki pengaruh positif dan signifikan terhadap kinerja UMKM kuliner di Jakarta Barat dikarenakan juga dengan adanya orientasi kewirausahaan yang diterapkan dalam suatu usaha maka dapat memungkinkan usaha tersebut dapat terus berkembang dan bersaing dengan pesaing lainnya

\section{DAFTAR PUSTAKA}

Bernoff, J. and Li, C. (2008), "Harnessing the power of the oh-so-social web", MIT Sloan Management Review, Vol. 49 No. 3, pp. 36-42.

Goh, K.-Y., Heng, C.-S. and Lin, Z. (2013), "Social media brand community and consumer behavior: quantifying the relative impact of user-and marketer-generated content", Information Systems Research, Vol. 24 No. 1, pp. 88-107.

Ghozali, D. G. (2016). Partial Least Squares: Regression \& Structural Equation Models. In G. David Garson and Statistical Associates Publishing.

Ghozali, Imam. (2014). Structural Equation Modeling Metode Alternatif dengan Partial Least Square.

Hsu, Y.-L. (2012), "Facebook as international emarketing strategy of Taiwan hotels", International Journal of Hospitality Management, Vol. 31 No. 1, pp. 972-980.

Keh, H.K., Nguyen, T.T.M. and Ng, H.P. (2007), "The effect of entrepreneurial orientation and marketing information on the performance of SMEs", Journal of Business Venturing, Vol. 22 No. 4, pp. 592-611.

Kraus, S. (2013). The role of entrepreneurial orientation in service firms: empirical evidence from Austria. The Service Industries Journal, 33(5), 427-444.

Li, C. and Bernoff, J. (2008), Groundswell: Winning in a World Transformed by Social Technologies, 1st ed., Harvard Business School Press, Boston, MA.

Lumpkin, G.T. and Dess, G. (1996), "Clarifying the entrepreneurial orientation construct and linking it to performance", Academy of Management Review, Vol. 21 No. 1, pp. 135172.

Malhotra. (2020). Marketing Research: Applied Insight.

Moullin, M. (2007). Performance measurement definitions: Linking performance measurement and organisational excellence. International journal of health care quality assurance, 20(3), 181-183

Rodriguez, M., Ajjan, H. and Peterson, R.M. (2016), "Social media in large sales forces: an empirical study of the impact of sales process capability and relationship performance", Journal of Marketing Theory and Practice, Vol. 24 No. 3, pp. 365-379.

Smart, D. T., \& Conant, J. S. (1994). Entrepreneurial orientation, distinctive marketing competencies and organizational performance. Journal of applied business research, $10,28-28$.

Sekaran, U. and Bougie, R. (2010), Research Methods for Business: A Skill Building Approach, Wiley, London.

Sugiyono, (2012) Metode Penelitian Pendidikan (Pendekatan Kuantitatif, Kualitatif, dan $R \& D)$, Bandung: Alfabeta 
Wiklund, J. and Shepherd, D. (2003), "Knowledge base resources, entrepreneurial orientation and the performance of small and medium sized businesses", Strategic Management Journal, Vol. 24 No. 12, pp. 1307-1314. 